\title{
EFISIENSI PEMASARAN KAYU SENGON (Falcataria moluccana) DI AREAL HUTAN RAKYAT PEKON LENGKUKAI, KABUPATEN TANGGAMUS, PROVINSI LAMPUNG
}

(Marketing Efficiency of Sengon (Falcataria moluccana) Wood in Lengkukai Village, Tanggamus District, Lampung Province)

\author{
Rian Betti Kusuma, Hari Kaskoyo, dan/and Rommy Qurniati*
}

Jurusan Kehutanan, Universitas Lampung

Jl. Prof. Sumantri Brojonegoro No. 1 Bandar Lampung, Lampung, Indonesia 35145

*E-mail: rommy.qurniati@fp.unila.ac.id

Tanggal diterima: 3 Agustus 2020; Tanggal disetujui: 28 September 2020; Tanggal direvisi: 22 Oktober 2020

\section{ABSTRACT}

Wood demand has increased, but wood supply from natural forests and industrial plantations has decreased. Small scale privately owned forest is an alternative to meet wood needs. To ensure the sustainability of small scale privately owned forest, it should provide high profit for the farmers and that can only be achieved by eficiency in the wood marketing. This study aimed to analyzed the efficiency of sengon wood marketing in Pekon Lengkukai Village. The research was conducted in January-February 2020. Data was collected through observation, documentation studies, and interviews with farmers and traders. Respondents consisted of 52 sengon wood farmers selected by simple random sampling and 10 marketing institutions (3 sawmills, 2 traders, and 5 loggers) selected by snowball sampling. The data were analyzed through marketing channels and market performance by using share and profit margin ratio calculation. The results identified four channels of sengon wood marketing, namely: (1) farmers - end consumers (2) farmers - sawmill - consumers, (3) farmers - collectors traders - sawmill - consumers, and (4) farmers - wood cutters - collector - sawmill - consumer. Sawmill has significant influence on marketing and achieved the highest ratio of profit margins. Based on the ratio of profit margins and share price at the farm level, the marketing of sengon wood in Lengkukai Village is inefficient. The bargaining position of farmers needs to be improved, by forming farmer groups as a marketing institution that accommodates and promotes farmer's sengon wood, and open farmer's access to market information and capital credit.

Keywords: Market performance, marketing channel, marketing institution, margin, sawmill

\begin{abstract}
ABSTRAK
Kebutuhan pasokan kayu mengalami peningkatan, tetapi kayu dari hutan alam dan hutan tanaman industri mengalami penurunan. Hutan rakyat menjadi alternatif untuk memenuhi kebutuhan ini. Untuk menjaga kelestarian hutan rakyat, maka petani sebagai pengelolanya harus mendapatkan keuntungan yang tinggi, hal ini dapat tercapai jika pemasarannya efisiensi. Tujuan penelitian ini untuk menganalisis efisiensi pemasaran kayu sengon di Pekon Lengkukai, Kabupaten Tanggamus, Provinsi Lampung. Penelitian dilaksanakan bulan Januari-Februari 2020. Pengambilan data dilakukan melalui observasi lapang, studi dokumentasi dan wawancara pada petani kayu sengon serta lembaga pemasaran yang terlibat. Responden petani kayu sengon yang diwawancara, meliputi 52 orang petani yang dipilih secara acak sederhana, dan 10 lembaga pemasaran (3 sawmill, 2 pedagang
\end{abstract}


pengumpul, dan 5 penebang kayu) yang dipilih menggunakan metode snowball sampling. Data yang diperoleh dianalisis berdasarkan saluran pemasaran dan keragaan pasar melalui perhitungan share dan ratio profit margin. Hasil penelitian mengidentifikasi empat saluran pemasaran kayu sengon di Pekon Lengkukai, Kabupaten Tanggamus, yaitu: (1) petani konsumen akhir (2) petani - sawmill - konsumen akhir, (3) petani - pedagang pengumpul sawmill - konsumen akhir, dan (4) petani - penebang kayu - pedagang pengumpul - sawmill - konsumen akhir. Sawmill memiliki pengaruh besar terhadap pemasaran kayu sengon dan juga memperoleh rasio profit margin tertinggi. Berdasarkan ratio profit margin dan share harga di tingkat petani, maka pemasaran kayu sengon di Pekon Lengkukai belum efisien. Untuk pemasaran lebih efisiensi, posisi tawar petani perlu ditingkatkan dengan membentuk kelompok tani sebagai lembaga pemasaran untuk menampung dan memasarkan kayu sengon dari petani, dan membuka akses petani pada informasi pasar kayu sengon dan kredit permodalan.

\section{Kata kunci: Keragaan pasar, lembaga pemasaran, margin, saluran pemasaran, sawmill}

\section{PENDAHULUAN}

Hutan rakyat merupakan hutan tanaman kayu yang dibangun dan dikelola oleh petani di atas lahan miliknya. Hutan rakyat bertujuan untuk mengembangkan kayu dengan pola tanam campuran (agroforestri) ataupun monokultur (Risasmoko, Hardjanto, \& Sundawati, 2016). Bentuk pengelolaan hutan rakyat sangat ditentukan oleh pemilik lahan dan profesinya, dimana pola agroforestri merupakan pola tanam yang paling umum dikembangkan petani (Zainuddin \& Sribianti, 2018). Keberadaan agroforestri menjadi alternatif dalam mengatasi permasalahan kebutuhan sumber daya hutan untuk memenuhi sumber bahan baku kayu (Widyaningsih \& Diniyati, 2010). Agroforestri yang dikembangkan di hutan rakyat diharapkan mampu memperbaiki produktivitas lahan, karena dapat menghasilkan tidak hanya kayu namun juga hasil pertanian, sehingga dapat meningkatkan pendapatan petani dan memperbaiki fungsi hutan dari aspek ekologi dan sosial. Jenis yang ditanam di areal hutan rakyat, antara lain sengon (Falcataria moluccana (Miq.) Barneby \& J.W.), durian (Durio zibethinus Murray.), jengkol (Pithecellobium lobatum Benth.), petai (Parkia speciose Hassk.), mahoni (Swietenia macrophylla King.), afrika
(Veronia amygdalina Delile.), dan randu (Ceiba pentandra (L.) Gaertn.) (Pratiwi, Kaskoyo, \& Herwanti, 2019).

Sengon merupakan jenis yang banyak ditanam, karena memiliki sifat yang menguntungkan, yaitu sengon dapat tumbuh pada sebaran kondisi iklim yang luas, serta tidak menuntut persyaratan tempat tumbuh yang tinggi dan multiguna (Surata, 2017). Sengon selain digunakan sebagai bahan bangunan dan kayu pulp digunakan pula oleh industri penggergajian/panglong sebagai salah satu bahan dasar pembuatan kayu olahan (Priyanto, 2019). Kayu sengon memiliki harga yang terjangkau dibandingkan tanaman kehutanan lain, sehingga banyak menarik minat konsumen untuk membeli kayu olahan tersebut (Putra, Lestari, \& Affandi, 2015). Inilah yang mendorong dominansi hutan rakyat tanaman sengon, karena masih terbukanya pasar sengon yang dapat menampung hasil hutan rakyat (Irawanti, Prawesti, \& Ekawati, 2012).

Keberhasilan dan keberlanjutan usaha hutan rakyat dapat dilihat dari perkembangan sistem pengelolaan terutama dalam aspek pemasarannya (Risasmoko et al., 2016). Aspek pemasaran yang perlu diperhatikan dalam upaya meningkatkan arus barang dari produsen ke konsumen, adalah efisiensi pemasaran. Efisiensi pemasaran adalah distribusi keuntungan 
yang diterima masing-masing pelaku pemasaran meliputi produsen, lembaga pemasaran, dan konsumen (Wulandari Qurniati, \& Herwanti, 2018). Tingkat efisiensi pemasaran dapat dilihat dari perhitungan marjin pemasaran, besarnya biaya pemasaran, besarnya keuntungan pemasaran, besarnya bagian yang diterima oleh petani (farmer's share), dan besarnya bagian yang diterima oleh lembaga pemasaran (trader's share), serta tingkat efisiensi masing-masing lembaga pemasaran yang terlibat dalam proses tataniaga (Arbi, Thirtawati, \& Junaidi, 2018).

Petani harus memilih pembeli yang paling tepat untuk mengoptimalkan aktivitas pemasaran (Putri, Nurmalina, \& Burhanudin, 2018). Namun, masih ada petani yang memilih saluran yang tidak tepat, sehingga menyebabkan inefisiensi pada saluran pemasaran. Oleh karena itu penelitian efisiensi pemasaran kayu sengon dilakukan untuk memberikan informasi pasar yang efisien bagi petani kayu sengon. Beberapa penelitian tentang pemasaran kayu sengon tidak menjadikan petani sebagai objek penelitian, tetapi lebih fokus pada lembaga pemasaran sawmill seperti pada penelitian Utama, Febryano, Herwanti, \& Hidayat (2019) dan Paririe, Marwa, \& Panambe (2020). Kajian yang melibatkan petani sengon sebagai responden penting dilakukan, agar dapat memberikan informasi yang utuh kepada petani dan lembaga yang terlibat dalam pemasaran kayu sengon, terutama terkait bagaimana upaya untuk meningkatkan efisiensi pemasarannya agar dapat meningkatkan pendapatan petani secara signifikan. Tujuan penelitian ini untuk mengetahui efisiensi pemasaran kayu sengon di Pekon Lengkukai, Kecamatan Kelumbayan Barat, Kabupaten Tanggamus, Provinsi Lampung.

\section{METODOLOGI}

\section{A. Tempat dan Waktu Penelitian}

Penelitian ini dilaksanakan di Pekon Lengkukai, Kecamatan Kelumbayan Barat,
Kabupaten Tanggamus pada bulan JanuariFebruari 2020. Peta lokasi penelitian dapat dilihat pada Gambar 1.

\section{B. Pengumpulan Data}

Objek pada penelitian ini adalah petani hutan rakyat yang membudidayakan kayu sengon dan lembaga pemasaran kayu sengon. Populasi petani hutan rakyat di Pekon Lengkukai sebanyak 110 orang. Dari jumlah tersebut diambil sampel responden menggunakan rumus slovin (Supriyanto \& Iswandari, 2017) dengan batas error 10\%, sehingga didapatkan jumlah sampel petani sebanyak 52 responden. Responden petani dipilih secara acak sederhana. Responden lembaga pemasaran terdiri dari 3 sawmill, 5 penebang kayu, dan 2 pedagang pengumpul. Penentuan responden untuk lembaga pemasaran dilakukan dengan snowball sampling berdasarkan informasi dari petani dan mengikuti saluran pemasarannya.

Data yang dikumpulkan meliputi data primer dan sekunder. Pengambilan data primer melalui wawancara langsung dengan responden petani dan lembaga pemasaran kayu sengon. Data dari petani kayu sengon meliputi nama, umur, jenis kelamin, pendidikan, pekerjaan, jumlah anggota keluarga, status kepemilikan lahan, cara penjualan kayu sengon, dan harga jual kayu sengon. Data dari lembaga pemasaran kayu sengon terdiri dari jenis usaha, jenis dan jumlah alat, jumlah tenaga kerja, kapasitas produksi, harga beli kayu sengon dari petani, biaya-biaya yang dikeluarkan untuk pemasaran kayu (biaya transportasi dan biaya muat-bongkar kayu), kapasitas pembelian kayu per bulan, wilayah operasi dan konsumennya, jenis dan ukuran bahan baku, sumber pembelian, ukuran produk, dan harga jual produk.

Data sekunder diperoleh dari instansi terkait dan studi pustaka yang meliputi data tentang kondisi sosial ekonomi masyarakat, lokasi dan kondisi fisik lingkungan Pekon Lengkukai, hasil-hasil penelitian terkait pemasaran kayu sengon, dan informasi penunjang lainnya. 


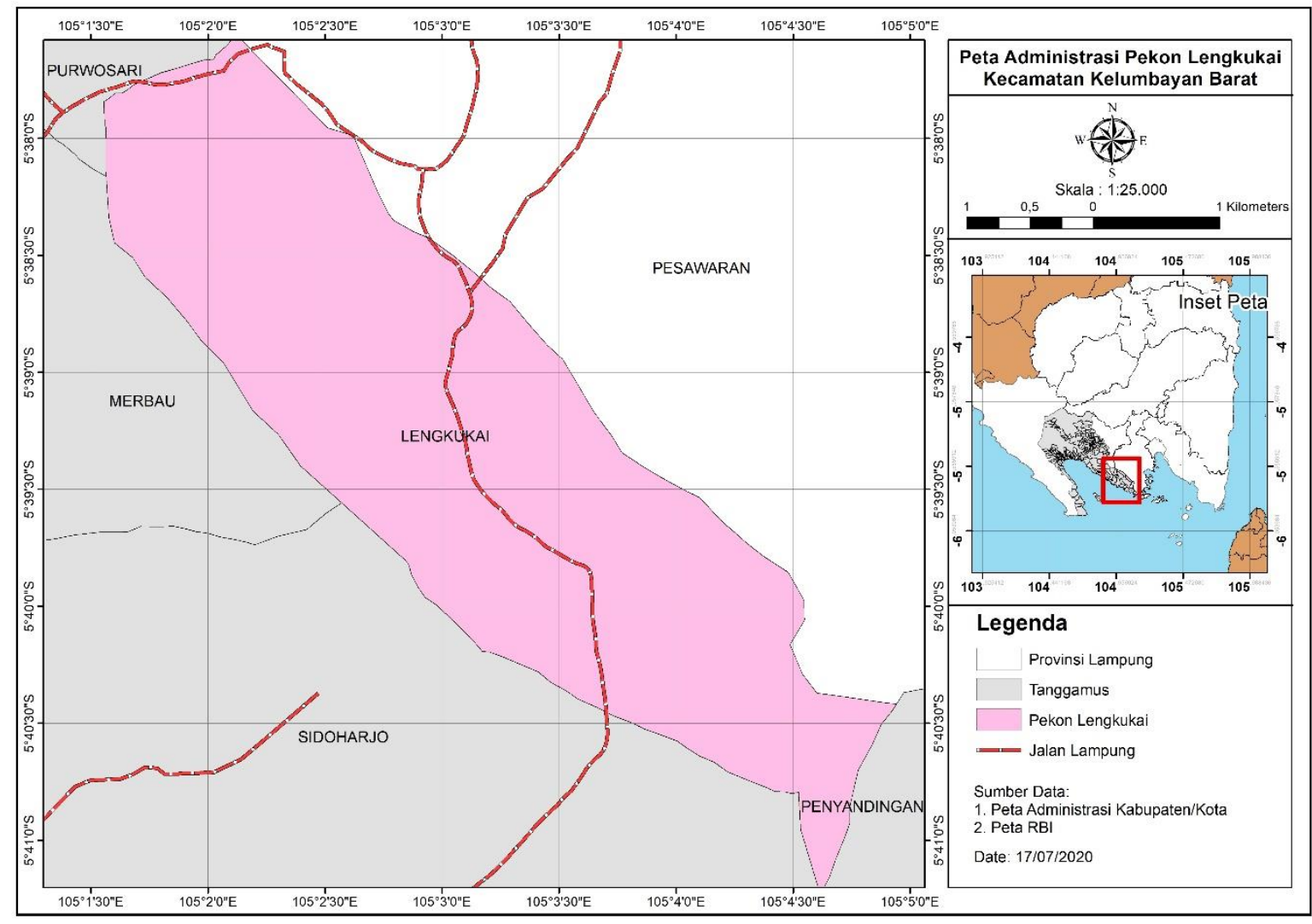

Sumber (Source): (Kusuma, 2020)

Gambar (Figure) 1. Lokasi penelitian (Research site)

\section{Analisis Data}

Efisiensi pemasaran dianalisis berdasarkan saluran pemasaran dan keragaan pasar. Saluran pemasaran dianalisis dengan melihat lembaga yang terlibat dalam pemasaran kayu sengon dan fungsi pemasaran kayu sengon di Pekon Lengkukai. Keragaan pasar dianalisis melalui Rasio Profit Margin (RPM) dan farmer's share (bagian petani) yang dibagi menjadi tiga bagian, yaitu produk log, balok, kasau dan papan. Kasau dan papan menjadi satu bagian karena memiliki saluran yang sama. Menurut Hasyim (2012) margin pemasaran, margin keuntungan, RPM, dan farmer's share dapat dihitung dengan rumus sebagai berikut.

\section{a. Margin pemasaran}

$M P=P r-P f$

Keterangan (Remarks):
$\mathrm{MP}=$ Margin pemasaran (Marketing margin) $\left(\mathrm{Rp} / \mathrm{m}^{3}\right)$

$\operatorname{Pr}=$ Harga ditingkat pedagang (Price of marketing institution) $\left(\mathrm{Rp} / \mathrm{m}^{3}\right)$ Harga ditingkat petani (Farmer

Pf $=$ price $)\left(\mathrm{Rp} / \mathrm{m}^{3}\right)$

\section{b. Margin keuntungan}

$\pi \mathrm{i}=\mathrm{MP}_{\mathrm{i}}-\mathrm{bti}$

Keterangan (Remarks):

$\pi \mathrm{i} \quad=$ Margin keuntungan lembaga pemasaran tingkat ke-i (Profit margin of marketing institution by $i^{\text {th }}$ level) $\left(\mathrm{Rp} / \mathrm{m}^{3}\right)$

$\mathrm{MP}_{\mathrm{i}}=$ Margin pemasaran tingkat ke-i (Marketing margin by $i^{\text {th }}$ level) $\left(\mathrm{Rp} / \mathrm{m}^{3}\right)$

Bti = Biaya pemasaran lembaga pemasaran tingkat ke-i (Marketing costs of marketing institution by $i^{\text {th }}$ level) $\left(\mathrm{Rp} / \mathrm{m}^{3}\right)$ 


\section{c. Ratio Profit Margin (RPM)}

$R P M=\frac{\pi i}{b t i}$

Keterangan (Remarks):

RPM = Rasio margin laba (Ratio profit margin )

bti $=$ Total biaya pemasaran lembaga pemasaran tingkat ke-i (Total marketing costs of marketing institution by $i^{\text {th }}$ level $)\left(\mathrm{Rp} / \mathrm{m}^{3}\right)$

\section{d. Farmer's share (Bagian petani)}

$S p=\frac{P f}{P r} \times 100 \%$

Keterangan (Remarks):

$\mathrm{Sp}=$ Bagian harga yang diterima petani (Farmer share) (\%)

$\mathrm{Pf}=$ Harga ditingkat petani (Farmer price) $\left(\mathrm{Rp} / \mathrm{m}^{3}\right)$

Pr = Harga ditingkat lembaga pemasaran (Price of marketing institution) $\left(\mathrm{Rp} / \mathrm{m}^{3}\right)$

\section{HASIL DAN PEMBAHASAN}

\section{A. Hasil}

\section{Pengembangan tanaman sengon di areal hutan rakyat}

Pengembangan hutan tanaman sengon di Pekon Lengkukai dilakukan petani di lahan milik atau yang dikenal dengan hutan rakyat. Penanaman dilakukan dengan pola monokultur dan campuran (agroforestri), namun yang lebih banyak dikembangkan adalah pola agroforestri dengan campuran berbagai jenis tanaman perkebunan seperti kopi, kakao, lada atau tanaman buah seperti durian. Pola agroforestri yang dipilih petani di lokasi penelitian mampu meningkatkan fungsi hutan secara ekonomi, ekologi, dan sosial.

Tanaman sengon merupakan sumber penghasilan sampingan petani dan penghasilan utamanya adalah dari tanaman kopi, kakao, dan lada. Sebanyak $44 \%$ petani Pekon Lengkukai memiliki luas lahan rata- rata 0,5 ha. Lahan yang digunakan oleh petani sengon adalah milik sendiri yang sebagian besar didapatkan dari tanah warisan orang tua atau membeli dari orang lain.

Jumlah tanaman sengon per ha yang ditanam petani di Pekon Lengkukai pada lahan agroforestri berbeda-beda, disesuaikan dengan ketersedian lahan karena pada umumnya lahan tersebut sudah ada jenis tanaman lain. Umumnya petani menanam kayu sengon dengan jarak tanam $3 \mathrm{~m}$ x $6 \mathrm{~m}$ pada sistem agroforestri, dan $2 \mathrm{~m}$ x $2 \mathrm{~m}$ pada sistem monokultur. Rata-rata jumlah pohon sengon per ha yang dihitung dari 52 petani sengon adalah 269 batang, dengan jumlah pohon paling sedikit 30 batang dan paling banyak 1.800 batang per ha. Jumlah pohon sengon keseluruhan di Pekon Lengkukai adalah 13.975 pohon. Berdasarkan informasi dari petani, volume kayu sebesar 0,26 $\mathrm{m}^{3}$ per pohon. Volume tersebut dihitung berdasarkan diameter pohon rata-rata, tinggi pohon rata-rata, angka bentuk pohon masing masing sebesar 24,5 cm, $8 \mathrm{~m}$ dan 0,7 (Bakti, Supriono, \& Meiganati, 2018). Maka potensi volume kayu pada umur lima tahun diperkirakan sebesar 3.633,50 $\mathrm{m}^{3}$. Harga kayu sengon saat ini adalah $\mathrm{Rp} 116.000,00 / \mathrm{m}^{3}$, dengan demikian potensi ekonomi sengon per tahun adalah Rp 421.486.000,00 per lima tahun atau Rp 84.297.200,00 per tahun. Nilai ini adalah potensi nilai bruto kayu sengon di Pekon Lengkukai sebelum dikurangi biayabiaya operasionalnya.

\section{Saluran pemasaran}

Saluran pemasaran diidentifikasi melalui aliran arus barang yang dilalui oleh lembaga pemasaran dari petani (produsen) sampai dengan konsumen akhir. Lembagalembaga yang terlibat dalam pemasaran kayu sengon di Pekon Lengkukai, yaitu penebang kayu, pedagang pengumpul, dan industri penggergajian kayu (sawmill). Lembaga-lembaga tersebut membentuk saluran pemasaran kayu sengon sebagai berikut (Gambar 2). 
Pola saluran pemasaran kayu sengon di Pekon Lengkukai terdiri dari empat saluran pemasaran. Dalam memasarkan hasil produksinya, petani pada saluran satu langsung menjual ke konsumen akhir yang umumnya adalah konsumen rumah tangga yang berdomisili dekat dengan tempat tinggal petani atau dekat dengan lokasi hutan rakyat. Kayu ini oleh konsumen akhir digunakan sebagai bahan bangunan.

Konsumen akhir adalah pengguna atau pemanfaat akhir dari kayu sengon untuk dikonsumsi sendiri. Konsumen akhir dalam penelitian ini terdiri dari dua kelompok. Konsumen pertama adalah pembeli yang berada di lokasi penelitian yang membeli kayu dari petani untuk membangun rumah.

Saluran (Channel) 1

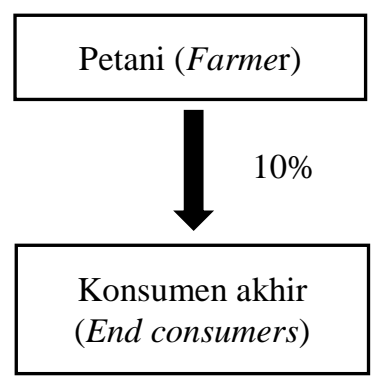

Saluran (Channel) 2

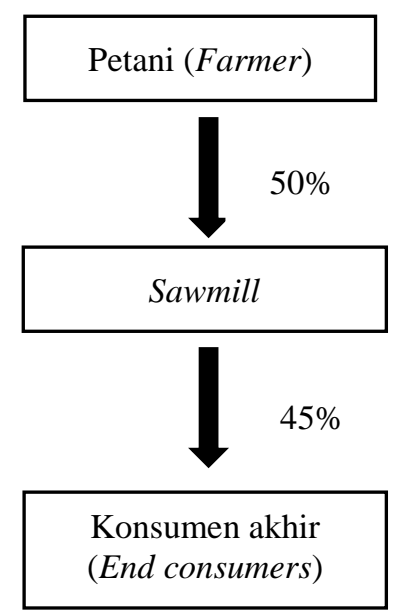

Konsumen akhir (End consumers)
Konsumen akhir ini menyewa penebang kayu dan serkel (sawmill keliling) untuk menebang pohon yang dibeli dari petani. konsumen kedua, yaitu semua lembaga pemasaran dan konsumen yang berada di luar Kabupaten Tanggamus, ini disebut konsumen akhir karena batasan penelitian hanya sampai pada wilayah Kabupaten Tanggamus.

Lembaga-lembaga pemasaran kayu sengon di Pekon Lengkukai menjalankan berbagai fungsi pemasaran agar kayu sengon dapat sampai ke konsumen akhir. Fungsi-fungsi pemasaran yang dilakukan lembaga pemasaran di Pekon Lengkukai meliputi fungsi pertukaran, fisik, dan fasilitas (Tabel 1).

\section{Saluran (Channel) 3 Saluran (Channel) 4}

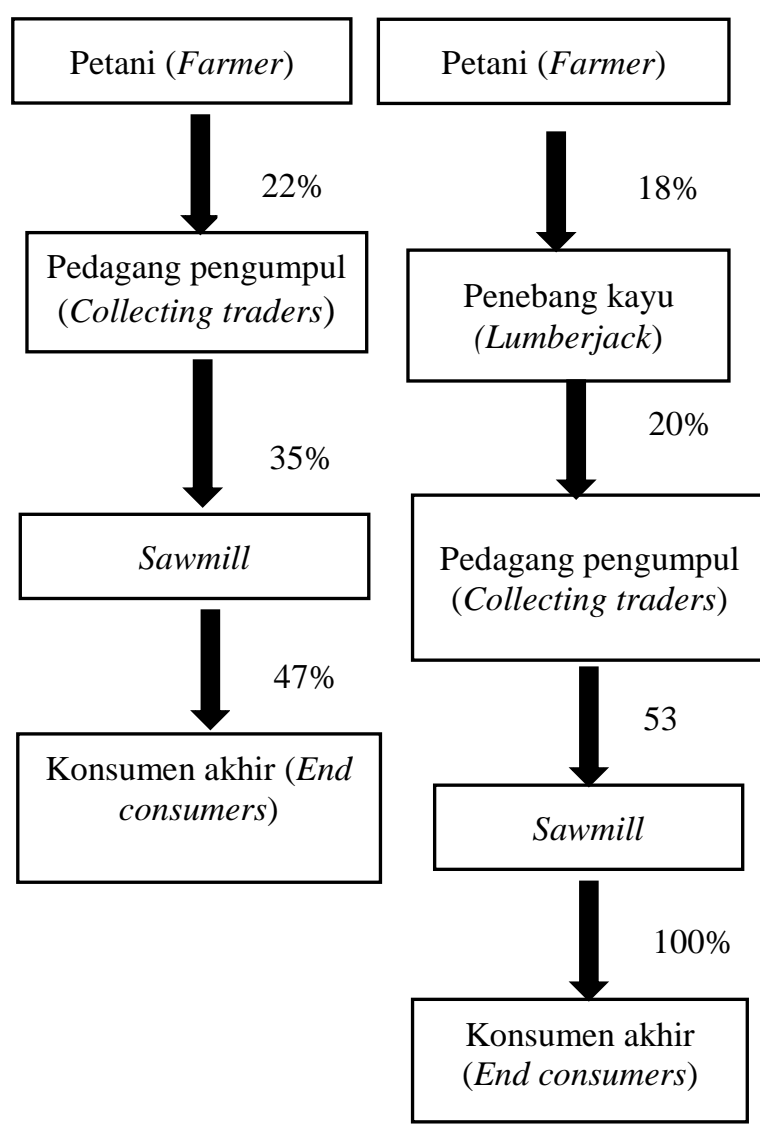

Gambar (Figure) 2. Saluran pemasaran kayu sengon di Pekon Lengkukai (Marketing channel of sengon in Pekon Lengkukai Village) 
Tabel (Table) 1. Fungsi-fungsi pemasaran kayu sengon di Pekon Lengkukai (The functions of sengon wood marketing in Lengkukai Village)

\begin{tabular}{|c|c|c|c|c|c|c|c|}
\hline \multirow{3}{*}{$\begin{array}{l}\text { Lembaga pemasaran } \\
\text { (Marketing agency) }\end{array}$} & \multicolumn{7}{|c|}{ Fungsi pemasaran (Marketing function) } \\
\hline & \multicolumn{2}{|c|}{ Pertukaran (Exchange) } & \multicolumn{2}{|c|}{ Fisik (Physical) } & \multicolumn{3}{|c|}{ Fasilitas (Amenities) } \\
\hline & $\begin{array}{l}\text { Penjualan } \\
\text { (Sales) }\end{array}$ & $\begin{array}{l}\text { Pembelian } \\
\text { (Purchase) }\end{array}$ & $\begin{array}{l}\text { Penyimpanan } \\
\text { (Storage) }\end{array}$ & $\begin{array}{l}\text { Pengangkutan } \\
\text { (Transport) }\end{array}$ & $\begin{array}{c}\text { Informasi harga } \\
\text { (Price } \\
\text { information) }\end{array}$ & $\begin{array}{l}\text { Standardisasi \& } \\
\text { grading } \\
\text { (Standardization } \\
\& \text { grading) } \\
\end{array}$ & $\begin{array}{l}\text { Penanggungan } \\
\text { resiko (Taking } \\
\text { the risk) }\end{array}$ \\
\hline $\begin{array}{l}\text { 1. Penebang kayu } \\
\text { (Lumberjack) }\end{array}$ & $\sqrt{ }$ & $\sqrt{ }$ & - & - & $\sqrt{ }$ & - & - \\
\hline $\begin{array}{l}\text { 3. Pedagang pengumpul } \\
\text { (Collector trader) }\end{array}$ & $\sqrt{ }$ & $\sqrt{ }$ & - & $\sqrt{ }$ & $\sqrt{ }$ & - & - \\
\hline 4. Sawmill & $\sqrt{ }$ & $\sqrt{ }$ & $\sqrt{ }$ & $\sqrt{ }$ & $\sqrt{ }$ & $\sqrt{ }$ & $\sqrt{ }$ \\
\hline
\end{tabular}

Fungsi pertukaran pada pemasaran kayu sengon berupa kegiatan penjualan dan pembelian. Kegiatan ini dilakukan oleh semua lembaga pemasaran. Penjualan kayu sengon di tingkat petani dilakukan dalam bentuk pohon berdiri. Cara ini dinilai sangat praktis oleh petani, karena kegiatan penebangan, pengurusan dokumen hingga pengangkutan ditanggung oleh pembeli. Penjualan yang dilakukan petani dilakukan dengan dua cara, yaitu secara borongan dan tebang butuh. Tebang butuh atau tebang pilih dilakukan petani pada saat ada keperluan mendesak atau kebutuhan yang penting. Sistem tebang pilih atau tebang butuh merupakan penjualan per unit dengan harga per meter kubik. Sistem ini memiliki keunggulan pada harga jual yang lebih tinggi, yaitu rata-rata Rp $525.000,00 / \mathrm{m}^{3}$ dibandingkan dengan harga rata-rata pada sistem borongan Rp 375.000,00/ $\mathrm{m}^{3}$. Pohon yang dijual biasanya dipilih yang berdiameter $20-30 \mathrm{~cm}$ dan dijual ke tukang tebang dalam jumlah kecil, menyesuaikan dengan kebutuhan petani. Penjualan dalam jumlah besar dilakukan secara borongan.

Pada sistem borongan, semua kayu yang ada di lahan tersebut dibeli dengan harga total untuk semua kayu yang akan dijual tanpa menghitung harga per meter kubik. Semua biaya pada sistem ini ditanggung oleh pembeli, sehingga tidak ada biaya apapun yang ditanggung oleh petani. Pembelian dengan sistem borongan dilakukan oleh pedagang pengumpul dan sawmill namun karena modal yang dimiliki terbatas, maka kuantitas pembelian oleh pedagang pengumpul lebih kecil dari sawmill.

Fungsi fisik terdiri dari fungsi pengangkutan dan penyimpanan. Fungsi pengangkutan dilakukan pedagang pengumpul dan sawmill mulai dari lokasi tebangan sampai penjualan ke konsumen akhir. Penebang kayu tidak melaksanakan fungsi pengangkutan karena penjualan kayu dilakukan di lokasi tebangan dan pengangkutan dilakukan oleh pembeli, yaitu pedagang pengumpul menggunakan kendaraan truk fuso. Fungsi penyimpanan dilakukan oleh sawmill karena sawmill melakukan penjualan dalam jumlah yang besar, sehingga kayu ditampung terlebih dahulu sebelum dipasarkan.

Fungsi fasilitas pemasaran kayu sengon terdiri dari informasi harga, standardisasi, grading, dan penanggungan resiko. Informasi harga yang diperoleh petani bersumber dari penebang kayu, pedagang, atau sesama petani yang telah menjual kayu sengon. Sementara itu penebang kayu, pedagang pengumpul, dan sawmill umumnya aktif mencari informasi perkembangan harga dari berbagai sumber guna mendapatkan harga terkini berikut spesifikasi kayunya. Oleh karena itu petani cenderung menjadi penerima harga (price taker). Standardisasi dan grading hanya dilakukan oleh sawmill karena kuantitas kayu yang dipasarkan oleh lembaga ini paling banyak. Standardisasi adalah proses penentuan spesifikasi ukuran dan bentuk produk log, balok, kasau, dan papan sedangkan grading adalah proses 
pengelompokkan produk kayu berdasarkan spesifikasi yang telah ditentukan. Standardisasi yang digunakan mengikuti perkembangan informasi harga pasar kayu sengon. Berdasarkan standardisasi ini sawmill melakukan perubahan bentuk pada kayu sengon (log) menjadi kayu gergajian seperti balok, kasau, dan papan. Risiko pemasaran kayu secara umum berada pada tingkat sawmill. Risiko ini muncul saat penyimpanan dan pengolahan atau perubahan bentuk kayu. Kualitas kayu yang beragam tentu memiliki tingkat keawetan kayu yang berbeda. Kayu berkualitas rendah memiliki resiko lebih tinggi pada saat proses pengangkutan, penyimpanan, dan pengolahan.

\section{Keragaan pasar}

Analisis keragaan pasar kayu sengon dilakukan dengan menggunakan analisis Ratio Profit Margin (RPM) dan farmer's share serta pengaruh saluran pemasaran yang berkenaan dengan harga di tiap lembaga pemasaran, biaya pemasaran, margin pemasaran, dan margin keuntungan. Analisis efisiensi pemasaran pada masingmasing saluran dapat dilihat pada Tabel 2, Tabel 3, dan Tabel 4.

Tabel (Table) 2. Keragaan pasar produk log (Market performance of log product)

\begin{tabular}{|c|c|c|c|c|c|c|c|c|}
\hline \multirow{3}{*}{ No. Uraian (Description) } & \multicolumn{8}{|c|}{ Produk log sengon (Sengon log products) } \\
\hline & \multicolumn{2}{|c|}{$\begin{array}{c}\text { Saluran } \\
(\text { Channel }) 1\end{array}$} & \multicolumn{2}{|c|}{$\begin{array}{l}\text { Saluran (Channel) } \\
2 \\
\end{array}$} & \multicolumn{2}{|c|}{$\begin{array}{c}\text { Saluran } \\
\text { (Channel) } 3\end{array}$} & \multicolumn{2}{|c|}{$\begin{array}{c}\text { Saluran } \\
\text { (Channel) } 4\end{array}$} \\
\hline & $\begin{array}{l}\text { Harga } \\
(\text { Price }) \\
\left(\mathrm{Rp} / \mathrm{m}^{3}\right)\end{array}$ & $\begin{array}{c}\text { Share } \\
(\%)\end{array}$ & $\begin{array}{l}\text { Harga } \\
(\text { Price }) \\
\left(\mathrm{Rp} / \mathrm{m}^{3}\right)\end{array}$ & $\begin{array}{l}\text { Share } \\
(\%)\end{array}$ & $\begin{array}{c}\text { Harga } \\
(\text { Price }) \\
\left(\mathrm{Rp} / \mathrm{m}^{3}\right)\end{array}$ & $\begin{array}{l}\text { Share } \\
(\%)\end{array}$ & $\begin{array}{l}\text { Harga } \\
(\text { Price }) \\
\left(\mathrm{Rp} / \mathrm{m}^{3}\right)\end{array}$ & $\begin{array}{c}\text { Share } \\
(\%)\end{array}$ \\
\hline \multicolumn{9}{|l|}{ 1. Petani (Farmer) } \\
\hline $\begin{array}{l}\text { - Harga jual pohon } \\
\text { berdiri (The selling } \\
\text { price of standing } \\
\text { trees) }\end{array}$ & 525.000 & 100 & 450.000 & 45,00 & 435.000 & 56,13 & 400.000 & 45,71 \\
\hline \multicolumn{9}{|l|}{$\begin{array}{l}\text { 2. Penebang kayu } \\
\text { (Wood cutter) }\end{array}$} \\
\hline $\begin{array}{l}\text { - Harga beli log } \\
\text { sengon (The } \\
\text { purchase price of } \\
\text { sengon logs) }\end{array}$ & - & - & - & - & - & - & 400.000 & 45,71 \\
\hline $\begin{array}{l}\text { - Harga jual kayu } \\
\text { sengon (The selling } \\
\text { price of sengon } \\
\text { wood) }\end{array}$ & - & - & - & - & - & - & 550.000 & 62,86 \\
\hline $\begin{array}{r}\text { - Biaya pemasaran } \\
\text { (Marketing costs) }\end{array}$ & - & - & - & - & - & - & 62.500 & 7,14 \\
\hline $\begin{array}{l}\text { - Transportasi } \\
\text { (Transportation) }\end{array}$ & - & - & - & - & - & - & 62.500 & 7,14 \\
\hline $\begin{array}{l}\text { - Margin pemasaran } \\
\text { (Marketing } \\
\text { margin) }\end{array}$ & - & - & - & - & - & - & 150.000 & 17,14 \\
\hline $\begin{array}{l}\text { - Margin keuntungan } \\
\text { (Profit margin) }\end{array}$ & - & - & - & - & - & - & 87.500 & . \\
\hline $\begin{array}{l}\text { - Ratio Profit } \\
\text { Margin }\end{array}$ & - & - & - & - & - & - & 1,40 & - \\
\hline $\begin{array}{l}\text { 3. Pedagang } \\
\text { pengumpul } \\
\text { (Collector trader) }\end{array}$ & & & & & & & & \\
\hline $\begin{array}{l}\text { - Harga beli log } \\
\text { sengon (The } \\
\text { purchase price of } \\
\text { sengon logs) }\end{array}$ & - & - & - & - & 435.000 & 56,13 & 550.000 & 62,86 \\
\hline
\end{tabular}


Efisiensi Pemasaran Kayu Sengon (Falcataria moluccana) di Areal Hutan Rakyat Pekon Lengkukai, Kabupaten Tanggamus, Provinsi Lampung

Rian Betti Kusuma, Hari Kaskoyo, dan/and Rommy Qurniati

Tabel (Table) 2. Lanjutan (Continuation)

\begin{tabular}{|c|c|c|c|c|c|c|c|c|}
\hline \multirow{4}{*}{ No. Uraian (Description) } & \multicolumn{8}{|c|}{ Produk log sengon (Sengon log products) } \\
\hline & \multicolumn{2}{|c|}{$\begin{array}{c}\text { Saluran } \\
\text { (Channel) } 1\end{array}$} & \multicolumn{2}{|c|}{$\begin{array}{c}\text { Saluran (Channel) } \\
2\end{array}$} & \multicolumn{2}{|c|}{$\begin{array}{c}\text { Saluran } \\
\text { (Channel) } 3\end{array}$} & \multicolumn{2}{|c|}{$\begin{array}{c}\text { Saluran } \\
\text { (Channel) } 4\end{array}$} \\
\hline & $\begin{array}{l}\text { Harga } \\
(\text { Price })\end{array}$ & Share & $\begin{array}{l}\text { Harga } \\
(\text { Price })\end{array}$ & Share & $\begin{array}{l}\text { Harga } \\
(\text { Price })\end{array}$ & Share & $\begin{array}{l}\text { Harga } \\
(\text { Price })\end{array}$ & Share \\
\hline & $\left(\mathrm{Rp} / \mathrm{m}^{3}\right)$ & $(\%)$ & $\left(\mathrm{Rp} / \mathrm{m}^{3}\right)$ & $(\%)$ & $\left(\mathrm{Rp} / \mathrm{m}^{3}\right)$ & $(\%)$ & $\left(\mathrm{Rp} / \mathrm{m}^{3}\right)$ & $(\%)$ \\
\hline $\begin{array}{l}\text { - Harga jual kayu } \\
\text { sengon (The selling } \\
\text { price of sengon } \\
\text { wood) }\end{array}$ & - & - & - & - & 550.000 & 70,97 & 675.000 & 77,14 \\
\hline $\begin{array}{l}\text { - Biaya pemasaran } \\
\text { (Marketing costs) }\end{array}$ & - & - & - & - & 62.500 & 8,06 & 68.750 & 7,86 \\
\hline $\begin{array}{l}\text { - Transportasi } \\
\text { (Transportation) }\end{array}$ & - & - & - & - & 50.000 & 6,45 & 50.000 & 5,71 \\
\hline $\begin{array}{l}\text { - Bongkar \& muat } \\
\text { (Unloading \& } \\
\text { loading) }\end{array}$ & - & - & - & - & 12.500 & 1,61 & 18.750 & 2,14 \\
\hline $\begin{array}{l}\text { - Margin pemasaran } \\
\text { (Marketing } \\
\text { margin) }\end{array}$ & - & - & - & - & 115.000 & 14,84 & 125.000 & 14,29 \\
\hline $\begin{array}{l}\text { - Margin } \\
\text { keuntungan (Profit } \\
\text { margin) }\end{array}$ & - & - & - & - & 52.500 & 6,77 & 56.250 & 6,43 \\
\hline $\begin{array}{l}\text { - Ratio Profit } \\
\text { Margin }\end{array}$ & - & - & - & - & 0,84 & - & 0,82 & - \\
\hline $\begin{array}{l}\text { 4. Penggergajian } \\
\text { (Sawmill) }\end{array}$ & & & & & & & & \\
\hline $\begin{array}{l}\text { - Harga beli log } \\
\text { sengon (The } \\
\text { purchase price of } \\
\text { sengon logs) }\end{array}$ & - & - & 450.000 & 45,00 & 550.000 & 70,97 & 675.000 & 77,14 \\
\hline $\begin{array}{l}\text { - Harga jual kayu } \\
\text { sengon (The selling } \\
\text { price of sengon } \\
\text { wood) }\end{array}$ & - & - & 1.000 .000 & 100,00 & 775.000 & 100,00 & 875.000 & 100,00 \\
\hline $\begin{array}{l}\text { - Biaya pemasaran } \\
\text { (Marketing costs) }\end{array}$ & - & - & 193.333 & 19,33 & 137.500 & 17,74 & 137.500 & 15,71 \\
\hline $\begin{array}{l}\text { - Transportasi } \\
\text { (Transportation) }\end{array}$ & - & - & 166.666 & 16,67 & 112.500 & 14,52 & 112.500 & 12,86 \\
\hline $\begin{array}{l}\text { - Bongkar \& muat } \\
\text { (Unloading \& } \\
\text { loading) }\end{array}$ & - & - & 26.666 & 2,67 & 25.000 & 3,23 & 25.000 & 2,86 \\
\hline $\begin{array}{l}\text { - Margin pemasaran } \\
\text { (Marketing } \\
\text { margin) }\end{array}$ & - & - & 550.000 & 55,00 & 225.000 & 29,03 & 200.000 & 22,86 \\
\hline $\begin{array}{l}\text { - Margin } \\
\text { keuntungan (Profit } \\
\text { margin) }\end{array}$ & - & - & 356.666 & 35,67 & 87.500 & 11,29 & 62.500 & 7,14 \\
\hline $\begin{array}{l}\text { - Ratio Profit } \\
\text { Margin }\end{array}$ & - & - & 1,84 & - & 0,64 & - & 0,45 & - \\
\hline $\begin{array}{l}\text { 5. Konsumen akhir } \\
\text { (Final consumer) }\end{array}$ & & & & & & & & \\
\hline $\begin{array}{l}\text { - Harga beli } \\
\text { (Purchase price) }\end{array}$ & 525.000 & - & 1.000 .000 & - & 775.000 & - & 875.000 & - \\
\hline
\end{tabular}


Tabel (Table) 3. Keragaan pasar produk balok sengon (Market performance of sengon beam product)

\begin{tabular}{|c|c|c|c|c|c|c|}
\hline \multirow{4}{*}{ Uraian (Description) } & \multicolumn{6}{|c|}{ Produk balok kayu sengon (Sengon wood block products) } \\
\hline & \multicolumn{2}{|c|}{ Saluran 2 (Channel 2) } & \multicolumn{2}{|c|}{ Saluran 3 (Channel 3) } & \multicolumn{2}{|c|}{ Saluran 4 (Channel 4) } \\
\hline & $\begin{array}{l}\text { Harga } \\
\text { (Price) }\end{array}$ & Share & $\begin{array}{l}\text { Harga } \\
\text { (Price) }\end{array}$ & Share & $\begin{array}{l}\text { Harga } \\
(\text { Price })\end{array}$ & Share \\
\hline & $\left(\mathrm{Rp} / \mathrm{m}^{3}\right)$ & $(\%)$ & $\left(\mathrm{Rp} / \mathrm{m}^{3}\right)$ & $(\%)$ & $\left(\mathrm{Rp} / \mathrm{m}^{3}\right)$ & $(\%)$ \\
\hline \multicolumn{7}{|l|}{ 1. Petani (Farmer) } \\
\hline $\begin{array}{l}\text { - Harga jual pohon berdiri } \\
\text { (The selling price of } \\
\text { standing trees) }\end{array}$ & 450.000 & 34,62 & 435.000 & 41,43 & 400.000 & 40,00 \\
\hline \multicolumn{7}{|l|}{ 2. Penebang kayu (Lumberjack) } \\
\hline $\begin{array}{l}\text { - Harga beli (The purchase } \\
\text { price) }\end{array}$ & - & - & - & - & 400.000 & 40,00 \\
\hline $\begin{array}{l}\text { - Harga jual (The selling } \\
\text { price) }\end{array}$ & - & - & - & - & 550.000 & 55,00 \\
\hline $\begin{array}{l}\text { - Biaya pemasaran } \\
\text { (Marketing costs) }\end{array}$ & - & - & - & - & 62.500 & 6,25 \\
\hline $\begin{array}{l}\text { - Transportasi } \\
\text { (Transportation) }\end{array}$ & - & - & - & - & 62.500 & 6,25 \\
\hline $\begin{array}{l}\text { - Margin pemasaran } \\
\text { (Marketing margin) }\end{array}$ & - & - & - & - & 150.000 & 15,00 \\
\hline $\begin{array}{l}\text { - Margin keuntungan (Profit } \\
\text { Margin) }\end{array}$ & - & - & - & - & 87.500 & 8,75 \\
\hline - Ratio Profit Margin & - & - & - & - & 1,4 & - \\
\hline \multicolumn{7}{|l|}{$\begin{array}{l}\text { 3. Pedagang pengumpul } \\
\text { (Collector trader) }\end{array}$} \\
\hline $\begin{array}{l}\text { - Harga beli (The purchase } \\
\text { price) }\end{array}$ & - & - & 435.000 & 41,43 & 550.000 & 55,00 \\
\hline $\begin{array}{l}\text { - Harga jual (The selling } \\
\text { price) }\end{array}$ & - & - & 550.000 & 52,38 & 675.000 & 67,50 \\
\hline $\begin{array}{l}\text { - Biaya pemasaran } \\
\text { (Marketing costs) }\end{array}$ & - & - & 62.500 & 5,95 & 68.750 & 6,88 \\
\hline $\begin{array}{l}\text { - Transportasi } \\
\text { (Transportation) }\end{array}$ & - & - & 50.000 & 4,76 & 50.000 & 5,00 \\
\hline $\begin{array}{l}\text { - Bongkar \& muat } \\
\text { (Unloading \& loading) }\end{array}$ & - & - & 12.500 & 1,19 & 18.750 & 1,88 \\
\hline $\begin{array}{l}\text { - Margin pemasaran } \\
\text { (Marketing margin) }\end{array}$ & - & - & 115.000 & 10,95 & 125.000 & 12,50 \\
\hline $\begin{array}{l}\text { - Margin keuntungan (Profit } \\
\text { Margin) }\end{array}$ & - & - & 52.500 & 5,00 & 56.250 & 5,63 \\
\hline - Ratio Profit Margin & - & - & 0,84 & - & 0,82 & - \\
\hline $\begin{array}{l}\text { 4. Sawmill } \\
\text { - Harga beli } \\
\text { (The purchase price) }\end{array}$ & 450.000 & 34,62 & 550.000 & 52,38 & 675,000 & 67,50 \\
\hline $\begin{array}{l}\text { - Harga jual } \\
\text { (The selling price) }\end{array}$ & 1.300 .000 & 100 & 1.050 .000 & 100 & 1.000 .000 & 100 \\
\hline $\begin{array}{l}\text { - Biaya pemasaran } \\
\text { (Marketing costs) }\end{array}$ & 193.333 & 14,87 & 137.500 & 13,10 & 150.000 & 15,00 \\
\hline $\begin{array}{l}\text { - Transportasi } \\
\text { (Transportation) }\end{array}$ & 166.666 & 12,82 & 112.500 & 10,71 & 125.000 & 12,50 \\
\hline $\begin{array}{l}\text { - Bongkar \& muat } \\
\text { (Unloading \& loading) }\end{array}$ & 26.666 & 2,05 & 25.000 & 2,38 & 25.000 & 2,50 \\
\hline $\begin{array}{l}\text { - Margin pemasaran } \\
\text { (Marketing margin) }\end{array}$ & 850.000 & 65,38 & 500.000 & 47,62 & 325.000 & 32,50 \\
\hline $\begin{array}{l}\text { - Margin keuntungan } \\
\text { (Profit Margin) }\end{array}$ & 656.666 & 50,51 & 362.500 & 34,52 & 175.000 & 17,50 \\
\hline $\begin{array}{l}\text { - Ratio Profit Margin } \\
\text { 5. Konsumer akhir (Final } \\
\text { consumer) }\end{array}$ & 3,40 & - & 2,64 & - & 1,17 & - \\
\hline $\begin{array}{l}\text { - Harga jual (The selling } \\
\text { price) }\end{array}$ & 1.300 .000 & & 1.050 .000 & & 1.000 .000 & - \\
\hline
\end{tabular}

Sumber (Source): Kusuma, 2020 
Efisiensi Pemasaran Kayu Sengon (Falcataria moluccana) di Areal Hutan Rakyat Pekon Lengkukai, Kabupaten Tanggamus, Provinsi Lampung

Rian Betti Kusuma, Hari Kaskoyo, dan/and Rommy Qurniati

Tabel (Table) 4. Keragaan pasar produk kasau dan papan (Market performance of kasau and board product)

\begin{tabular}{|c|c|c|c|c|c|}
\hline \multirow{4}{*}{ No. } & \multirow{4}{*}{ Uraian (Decription) } & \multicolumn{4}{|c|}{ Jenis kasau dan papan (Types of rafters and boards) } \\
\hline & & \multicolumn{2}{|c|}{ Saluran 3 (Channel 3) } & \multicolumn{2}{|c|}{ Saluran 4 (Channel 4) } \\
\hline & & Harga (Price) & Share & Harga (Price) & Share \\
\hline & & $\left(\mathrm{Rp} / \mathrm{m}^{3}\right)$ & $(\%)$ & $\left(\mathrm{Rp} / \mathrm{m}^{3}\right)$ & $(\%)$ \\
\hline \multicolumn{6}{|c|}{ 1. Petani (Farmer) } \\
\hline & $\begin{array}{l}\text { - Harga jual pohon berdiri (The } \\
\text { selling price of standing trees) }\end{array}$ & 357.000 & 20,83 & 400.000 & 25,00 \\
\hline \multicolumn{6}{|c|}{ 2. Penebang kayu (Lumberjack) } \\
\hline & $\begin{array}{l}\text { - Harga beli log sengon (The } \\
\text { purchase price of sengon logs) }\end{array}$ & - & - & 400.000 & 25,00 \\
\hline & $\begin{array}{l}\text { - Harga jual kayu sengon (The } \\
\text { selling price of sengon wood) }\end{array}$ & - & - & 550.000 & 34,38 \\
\hline & $\begin{array}{l}\text { - Biaya pemasaran (Marketing } \\
\text { costs) }\end{array}$ & - & - & 62.500 & 3,91 \\
\hline & - Sarad (Sharad) & - & - & 62.500 & 3,91 \\
\hline & $\begin{array}{l}\text { - Margin pemasaran (Marketing } \\
\text { margin) }\end{array}$ & - & - & 150.000 & 9,38 \\
\hline & $\begin{array}{l}\text { - Margin keuntungan (Profit } \\
\text { margin) }\end{array}$ & - & - & 87.500 & 5,47 \\
\hline & - Ratio Profit Margin & - & - & 1,4 & - \\
\hline \multicolumn{6}{|c|}{$\begin{array}{l}\text { 3. Pedagang pengumpul } \\
\text { trader) }\end{array}$} \\
\hline & $\begin{array}{l}\text { - Harga beli log sengon (The } \\
\text { purchase price of sengon logs) }\end{array}$ & 375.000 & 20,83 & 550.000 & 34,38 \\
\hline & $\begin{array}{l}\text { - Harga jual kayu sengon (The } \\
\text { selling price of sengon wood) }\end{array}$ & 550.000 & 30,56 & 675.000 & 42,19 \\
\hline & $\begin{array}{l}\text { - Biaya pemasaran (Marketing } \\
\text { price) }\end{array}$ & 112.500 & 6,25 & 68.750 & 4,30 \\
\hline & - Transportasi (Transportation) & 87.500 & 4,86 & 50.000 & 3,13 \\
\hline & $\begin{array}{l}\text { - Bongkar \& muat (Unloading } \\
\text { and loading) }\end{array}$ & 25.000 & 1,39 & 18.750 & 1,17 \\
\hline & $\begin{array}{l}\text { - Margin pemasaran (Marketing } \\
\text { margin) }\end{array}$ & 193.000 & 10,72 & 125.000 & 7,81 \\
\hline & $\begin{array}{l}\text { - Margin keuntungan (Profit } \\
\text { margin) }\end{array}$ & 80.500 & 4,47 & 56.250 & 3,52 \\
\hline & - Ratio Profit Margin & 0,72 & - & 0,82 & - \\
\hline \multicolumn{6}{|c|}{ 4. Sawmill } \\
\hline & $\begin{array}{l}\text { - Harga beli log sengon (The } \\
\text { purchase price of sengon logs) }\end{array}$ & 550.000 & 30,56 & 675.000 & 42,19 \\
\hline & $\begin{array}{l}\text { - Harga jual kayu sengon (The } \\
\text { selling price of sengon wood) }\end{array}$ & 1.800 .000 & 100 & 1.600 .000 & 100 \\
\hline & $\begin{array}{l}\text { - Biaya pemasaran (Marketing } \\
\text { costs) }\end{array}$ & 187.500 & 10,42 & 150.000 & 9,38 \\
\hline & - Transportasi (Transportation) & 150.000 & 8,33 & 125.000 & 7,81 \\
\hline & $\begin{array}{l}\text { - Bongkar \& muat (Unloading } \\
\text { and loading) }\end{array}$ & 37.500 & 2,08 & 25.000 & 1,56 \\
\hline & $\begin{array}{l}\text { - Margin pemasaran (Marketing } \\
\text { margin) }\end{array}$ & 1.250 .000 & 69,44 & 925.000 & 57,81 \\
\hline & $\begin{array}{l}\text { - Margin keuntungan (Profit } \\
\text { Margin) }\end{array}$ & 1.062 .500 & 59,03 & 775.000 & 48,44 \\
\hline & - Ratio Profit Margin & 5,67 & - & 5,17 & - \\
\hline 5. & $\begin{array}{l}\text { Konsumen akhir (Final } \\
\text { comsurmer) } \\
\text { - Harga beli (The purchase } \\
\text { price) }\end{array}$ & 1.800 .000 & - & 1.600 .000 & - \\
\hline
\end{tabular}

Sumber (Source): Kusuma, 2020 


\section{B. Pembahasan}

Saluran pemasaran yang dilalui kayu sengon dalam perjalanannya ke konsumen akhir memiliki kelebihan dan kelemahannya masing-masing. Menurut Lestari, Winarno, \& Premono (2015), semakin pendek dan sederhana suatu saluran pemasaran, maka akan semakin efisien. Selain itu, efisiensi pemasaran dapat juga terkait dengan biaya transaksi yang dikeluarkan di sepanjang jalur pemasaran. Sejalan dengan pendapat tersebut, saluran 1 pada pemasaran kayu sengon di Pekon Lengkukai sebagai saluran paling pendek memasarkan kayu sengon langsung dari petani ke konsumen akhir tanpa melibatkan lembaga perantara, sehingga tidak ada biaya pemasarannya (Tabel 1.). Biaya pemasaran pada penelitian ini adalah biaya yang dikeluarkan oleh semua lembaga pemasaran setelah kayu sengon meninggalkan titik petani (siap jual) hingga mencapai konsumen akhir. Pemasaran secara langsung ke konsumen akhir menyebabkan harga yang diterima petani paling tinggi dibandingkan dengan saluran lainnya, sehingga saluran ini adalah saluran yang paling menguntungkan bagi petani sengon tetapi saluran ini hanya digunakan pada produk log. Produk lain seperti balok, kasau, dan papan sebagai olahan log belum menggunakan saluran ini, karena petani belum dapat memproduksinya, sehingga petani tidak memasarkan kayu sengon dalam bentuk produk-produk tersebut. Padahal nilai tambah dari perubahan log menjadi produk-produk lain dapat menambah keuntungan petani dan keuntungan ini dapat menjadi daya tarik tersendiri bagi pengembangan hutan tanaman sengon di lahan petani.

Saluran 1 hanya digunakan oleh $10 \%$ petani (Gambar 2.) karena saluran ini hanya mampu menampung kuantitas kayu dalam jumlah terbatas. Keterbatasan ini menyebabkan petani tidak dapat mengandalkan saluran ini untuk pemasaran seluruh hasil kayu sengonnya, sehingga petani lebih banyak menggunakan Saluran 2.
Saluran 2 banyak digunakan petani karena mampu menampung kayu dalam kapasitas besar tetapi di sini petani tidak diuntungkan karena harga jual yang diterima rendah. Pada saluran ini petani menjual kayunya ke sawmill, penjualan ini didasari adanya keterikatan dengan sawmill. Sawmill memberikan bibit kayu sengon kepada petani untuk ditanam di lahan garapannya, kemudian pembayaran bibit dilakukan setelah proses pemanenan. Keterikatan penjualan ini menyebabkan keuntungan yang besar pada pemilik sawmill karena petani yang telah menerima pinjaman bibit dari sawmill tidak dapat menjual kayunya ke pihak lain. Kurangnya pengetahuan dan keterampilan petani dalam membuat bibit sengon sendiri serta keterbatasan modal dalam mengembangkan hutan tanaman sengon akhirnya mengikat petani pada tawaran bantuan modal bibit dari sawmill. Walaupun bantuan bibit ini diikuti dengan komitmen yang mengikat petani untuk menjual hasil tanaman sengonnya ke sawmill. Beberapa penelitian menunjukkan bahwa petani dapat memiliki kebebasan dalam memilih pedagang yang diinginkan apabila tidak ada keterikatan petani untuk berhutang dengan lembaga pemasaran manapun, baik dalam bentuk uang maupun barang (Rumallang, Jumiati, Akbar, \& Nandir, 2020; Dewi, Yusri, \& Saputra, 2018; \& Septya, Widayanti, Sudiyarto, \& Amir, 2018). Selain itu, kebebasan dalam menentukan saluran pemasaran yang akan dipilih petani juga ditentukan oleh informasi harga (pasar) yang dimilikinya. Saat ini petani sengon di Pekon Lengkukai masih sangat terbatas akses informasinya padahal menurut Parmar, Soni, Kuwornu, \& Salin (2019) informasi pasar memainkan peran yang penting dalam meningkatkan harga pasar dan keuntungan bagi petani.

Harga jual yang rendah di tingkat petani juga disebabkan karena petani menjual kayunya dalam bentuk pohon berdiri. Petani tidak memiliki modal yang cukup untuk melakukan penebangan, sehingga penjualan kayu, baik dengan 
sistem tebang butuh ataupun borongan, dilakukan dalam bentuk pohon berdiri. Penjualan dalam bentuk pohon berdiri ini juga dilakukan oleh petani kayu dari hutan rakyat di Ciamis Jawa Barat dan cara seperti ini menyebabkan posisi tawar petani lemah dalam penentuan harga (Sukadaryati, Yuniawati, \& Dulsalam, 2018).

Biaya pemasaran tertinggi untuk semua produk kayu sengon di semua saluran berada pada lembaga di tingkat sawmill (Tabel 2, Tabel 3 dan Tabel 4). Menurut Putri et al., (2018), besarnya biaya pemasaran dipengaruhi oleh fungsi pemasaran yang dilakukan oleh lembaga pemasaran tersebut. Pendapat ini sejalan dengan kondisi di Pekon Lengkukai karena sawmill menjalankan semua fungsi pemasaran sedangkan lembaga lain hanya beberapa fungsi saja (Tabel 1). Fungsi pemasaran mencakup beragam kegiatan yang dapat memperlancar dalam proses penyampaian barang atau jasa dari tingkat produsen hingga ke konsumen (Qurniati, 2019).

Pelaksanaan fungsi penyimpanan, standardisasi, grading, dan penanggungan resiko membutuhkan modal yang tidak sedikit, misalnya, fungsi penyimpanan membutuhkan tempat yang luas untuk menampung kayu dan menyimpannya sebelum diproses menjadi produk lain atau dipasarkan. Penyimpanan ini juga menunjukkan bahwa modal akan tertahan beberapa waktu selama proses penyimpanan berlangsung dan munculnya risiko kerusakan kayu selama proses penyimpanan. Namun ini terbayar dengan harga jual yang tinggi untuk mengembalikan semua biaya dan modal yang telah dikeluarkan oleh sawmill. Seperti yang dilakukan pedagang pengumpul kayu bambang lanang di Sumatera Selatan yang melakukan fungsi penyimpanan untuk menunggu harga yang tinggi sebelum menjualnya (Lestari et al., 2015).

Harga jual yang tinggi menyebabkan margin pemasaran, margin keuntungan, dan
RPM di tingkat sawmill pada semua produk kayu sengon paling tinggi (Tabel 2, Tabel 3, dan Tabel 4). Hal ini sejalan dengan pendapat Baladina et al., (2011) yang menyebutkan bahwa semakin tinggi harga jualnya, maka nilai margin pemasaran akan semakin besar. Margin pemasaran yang tinggi menyebabkan keuntungan tertinggi pada tingkat sawmill. Selain itu kemampuan sawmill mengendalikan biaya pemasaran membuat semakin tinggi RPM yang diperoleh.

Penyebaran RPM terhadap biaya pada lembaga pemasaran di setiap saluran kurang menyebar merata, secara teknis ini mengindikasikan bahwa pemasaran kayu sengon belum efisien. Hal ini sejalan dengan hasil penelitian Wulandari, Qurniati, \& Herwanti (2018) pada komoditi durian yang menyimpulkan bahwa pemasaran durian belum efisien karena penyebaran RPM terhadap biaya tidak merata pada setiap lembaga pemasaran. Selain indikator RPM, Hikmah \& Purnomo (2019) menambahkan efisiensi pemasaran dapat dilihat dari bagian yang diterima petani (farmer's share) pada setiap saluran pemasaran yang ada.

Share harga di tingkat petani adalah persentase nilai dari perbandingan harga jual di tingkat petani dengan harga beli di tingkat konsumen akhir (Prasetya, Qurniati, \& Herwanti, 2020). Share yang diterima petani pada pemasaran produk log lebih tinggi (Tabel 2) dibandingkan pada produk balok, kasau, dan papan (Tabel 3 dan 4). Namun secara umum share harga di tingkat petani masih rendah. Share yang rendah ini menurut Arbi, Thirtawati, \& Junaidi (2018) dapat disebabkan oleh banyaknya lembaga pemasaran yang terlibat. Kondisi ini terjadi tidak hanya pada pemasaran sengon namun juga komoditi lain seperti durian (Prasetya et al., 2020). Sehingga berdasarkan RPM dan share harga di tingkat petani maka, pemasaran kayu sengon di Pekon Lengkukai dapat dikatakan belum efisien. 


\section{KESIMPULAN DAN SARAN}

\section{A. Kesimpulan}

Pemasaran kayu sengon di Pekon Lengkukai terdiri dari empat saluran pemasaran dengan lembaga pemasaran yang terlibat adalah penebang kayu, pedagang pengumpul, dan industri penggergajian kayu (sawmill). Fungsi pemasaran tidak sepenuhnya dilakukan oleh masing-masing lembaga pemasaran, hanya sawmill yang melakukan semua fungsi pemasaran karena kekuatan modal yang dimilikinya. Keragaan pasar menunjukkan bahwa sawmill memiliki pengaruh besar terhadap pemasaran kayu sengon di Pekon Lengkukai dan juga memperoleh keuntungan tertinggi. Petani dalam memasarkan kayunya masih terikat pada sawmill karena adanya pinjaman bibit di awal penanaman. Keterbatasan modal dan informasi pasar yang dimiliki petani menyebabkan pasar kayu sengon belum efisien, ditunjukkan dengan RPM yang belum merata, dan rendahnya share harga yang diterima petani.

\section{B. Saran}

Hutan tanaman sengon dalam bentuk hutan rakyat yang dibangun petani akan lebih berkembang jika keuntungan yang diperoleh petani dalam sistem pemasaran kayu sengon dapat ditingkatkan. Petani perlu mendapat fasilitasi pelatihan untuk menyiapkan bibit sengon secara mandiri serta memperoleh kemudahan dalam mengakses pinjaman/kredit permodalan yang tidak mengikat agar petani tidak terikat dengan sawmill atau pihak manapun dalam mengembangkan usaha taninya. Selain itu perlu dibentuk kelompok tani sebagai lembaga pemasaran untuk menampung dan memasarkan kayu sengon dari petani agar petani memiliki kekuatan dalam menentukan harga jual yang lebih menguntungkan. Kelompok tani ini juga dapat membuka akses petani pada informasi pasar kayu sengon, sehingga petani memiliki pengetahuan yang cukup untuk memilih saluran pemasaran yang paling menguntungkan.

\section{UCAPAN TERIMA KASIH}

Penulis mengucapkan terima kasih kepada Dr. Wahyu Hidayat yang telah memberikan masukan dan saran dalam penelitian ini. Penulis juga mengucapkan terimakasih pada Prayogi Saiful Anwar, Jepry Saputra, Anggi Feriansyah, Prihandini Tri Octavia dan Ade Wahyu Nurjanah yang telah membantu dalam pengerjaan di lapangan.

\section{DAFTAR PUSTAKA}

Arbi, M., Thirtawati, T., \& Junaidi, Y. (2018). Analisis saluran dan tingkat efisiensi pemasaran beras semi organik di Kecamatan Rambutan Kabupaten Banyuasin. JSEP (Journal of Social and Agricultural Economics), 11(1), 22-32.

Baladina, N., Anindita, R., Rosidi, A., Pelletier, E., Smith, D., Hassan, M., Kim, J., Alemayehu, B., Cahyono, W., Marwanti, S., Sari, I.N., Winandi, R., \& Agribisnis, D. (2011). Analisis efisiensi pemasaran durian di Desa Wonoagung, Kecamatan Kasembon, Kabupaten Malang. Jurnal Habitat, 16(1), 59-66.

Bakti, G. F., Supriono, B., \& Meiganati, K. B. (2018). Pendugaan Potensi Tegakan dan Kontribusi Hutan Rakyat Terhadap Pendapatan Masyarakat di Kecamatan Cigudeg Kabupaten Bogor. Jurnal Nusa Sylva, 18(2), 9097.

Dewi, N., Yusri, J., \& Saputra, A.J. (2018). Analisis struktur perilaku dan kinerja pasar komoditi padi di Desa Bunga Raya dan Desa Kemuning Muda Kecamatan Bunga Raya Kabupaten Siak. Jurnal Agribisnis, 19(1), 42-56. Hasyim, A.I. (2012). Pengantar Tataniaga Pertanian. Fakultas Pertanian Universitas Lampung. 
Hikmah, H., \& Purnomo, A.H. (2019).

Saluran, margin dan efisiensi pemasaran rumput laut di Sentra Kawasan Minapolitan Kabupaten Sumbawa. Buletin Ilmiah Marina Sosial Ekonomi Kelautan dan Perikanan, 3(2), 61-69.

Irawanti, S., Prawesti, A., \& Ekawati, S. (2012). Manfaat ekonomi dan peluang pengembangan hutan rakyat sengon di Kabupaten Pati. Jurnal Penelitian Sosial dan Ekonomi Kehutanan, 9(3), 126-139.

Kusuma, R.B. (2020). Efisiensi pemasaran kayu sengon (Falcataria moluccana) di Pekon Lengkukai Kecamatan Kelumbayan Barat Kabupaten Tanggamus. Skripsi. Universitas Lampung.

Lestari, S., Winarno, B., \& Premono, B.T. (2015). Saluran pemasaran kayu pertukangan jenis bambang lanang (Michelia champaca) yang menguntungkan petani di Sumatera Selatan. Jurnal Penelitian Sosial dan Ekonomi Kehutanan, 12(2), 89-97.

Paririe, F.D., Marwa, J., \& Panambe, N. (2020). Tingkat pendapatan pengusaha kayu gergajian berdasarkan margin keuntungan dan alur pemasaran kayu lokal di Distrik Manokwari Utara. Jurnal Kehutanan Papuasia, 5(2), 196-206.

Parmar, I.S., Soni, P., Kuwornu, J.K.M., \& Salin, K.R. (2019). Evaluating farmers' access to agricultural information: evidence from Semi-Arid Region of Rajasthan State, India. Agriculture (Switzerland), 9(60), 1-17.

Prasetya, A.Y., Qurniati, R., \& Herwanti, S. (2020). Saluran dan margin pemasaran durian hasil agroforestri di Desa Sidodadi. Jurnal Belantara, 3(1), 3240.

Pratiwi, A.M., Kaskoyo, H., \& Herwanti, S. (2019). Efisiensi pemasaran agroforestri berbasis kopi berdasarkan keragaan pasar: studi kasus di Pekon Air Kubang, Tanggamus. Jurnal Sylva Lestari, 7(3), 299-308.
Priyanto, A. (2019). Laminasi kayu sengon sebagai salah satu solusi ketersediaan kayu untuk bahan bangunan. Taman Vokasi, 7(2), 182-188.

Putra, D.S.A., Lestari, D.A.H., \& Affandi, M.I. (2015). Kelayakan finansial dan prospek pengembangan agribisnis sengon (Albizia falcataria) rakyat di Kecamatan Kemiling Kota Bandar Lampung. JIIA, 3(4), 345-353.

Putri, R.K., Nurmalina, R., \& Burhanuddin, B. (2018). Analisis efisiensi dan faktor yang memengaruhi pilihan saluran pemasaran. Jurnal Ilmiah Manajemen, 8(1), 109-135.

Qurniati, R. (2019). Pemasaran Hasil Hutan. Buku. Graha ilmu. Yogyakarta.

Risasmoko, A., Sundawati, L., Hutan, D.M., \& Ipb, F.K. (2016). Kajian subsistem produksi dan pemasaran dalam pengembangan hutan rakyat. Jurnal Silvikultur Tropika, 7(1), 4552.

Rumallang, A., Jumiati, J., Akbar, A., \& Nandir, N. (2020). Analisis struktur, perilaku dan kinerja pemasaran kentang di Desa Erelembang Kecamatan Tombolopao Kabupaten Gowa. Jurnal Agrikultura, 30(3), 8390.

Septya, F., Widayanti, S., Sudiyarto, \& Amir, I.T. (2018). Struktur dan perilaku pasar beras surabaya. Jurnal Agridevina, 7(1), 27-39.

Sukadaryati, S., Yuniawati, Y., \& Dulsalam, D. (2018). Pemanenan kayu hutan rakyat (Studi kasus di Ciamis, Jawa Barat). Jurnal Ilmu Kehutanan, 12(2), 142-155.

Supriyanto, W., \& Iswandari, R. (2017). Kecenderungan Sivitas Akademika dalam memilih Sumber Referensi untuk Penyusunan Karya Tulis Ilmiah di Perguruan Tinggi. Berkala Ilmu Perpustakaan dan Informasi, 13(1), 79.

Surata, A. (2017). Analisis finansial pembibitan sengon (Albazia falcataria) (Studi kasus di UD Sarana 
Rejeqi, Kabupaten Banyumas). Jurnal Pertanian Agros, 19(2), 159-167.

Utama, R.C., Febryano, I.G., Herwanti, S., \& Hidayat, W. (2019). Saluran pemasaran kayu gergajian sengon (Falcataria moluccana) pada industri penggergajian kayu rakyat di Desa Sukamarga, Kecamatan Abung Tinggi, Kabupaten Lampung Utara. Jurnal Sylva Lestari, 7(2), 195-203.

Widyaningsih, T.S, \& Diniyati, D. (2010). Kontribusi ekonomi dan sistem pemasaran hasil hutan rakyat pola wanafarma di Majenang, CILACAP.
Jurnal Penelitian Sosial dan Ekonomi Kehutanan, 7(1), 55-71.

Wulandari, D., Qurniati, R., \& Herwanti, S. (2018). Efisiensi pemasaran durian (Durio zibethinus) di Desa Wisata Durian Kelurahan Sumber Agung. Jurnal Sylva Lestari, 2(6), 68-76.

Zainuddin, M., \& Sribianti, I. (2018). Pendapatan masyarakat pada komponen silvopasture dan agrisilvikultur di Kecamatan Parangloe Kabupaten Gowa. Jurnal Hutan dan Masyarakat, 10(1), 136144. 